\title{
Changes in Antarctic temperature, wind and precipitation in response to the Antarctic Oscillation
}

\author{
Michiel R. van den BROEKE, ${ }^{1}$ Nicole P. M. van LIPZIG $^{2 *}$ \\ ${ }^{1}$ Institute for Marine and Atmospheric Research Utrecht, P.O. Box 80.005, Utrecht University, Princetonplein 5, \\ 3508 TA Utrecht, The Netherlands \\ E-mail: broeke@phys.uu.nl \\ ${ }^{2}$ Royal Netherlands Meteorological Institute, Postbus 201, 3730 AE De Bilt, The Netherlands
}

\begin{abstract}
Output of a 14 year integration with a high-resolution $(55 \mathrm{~km} \times 55 \mathrm{~km})$ regional atmospheric climate model is used to study the response of Antarctic near-surface climate to the Antarctic Oscillation (AAO), the periodical strengthening and weakening of the circumpolar vortex in the Southern Hemisphere. In spite of the relatively short record, wind, temperature and precipitation show widespread and significant AAO-related signals. When the vortex is strong (high AAO index), northwesterly flow anomalies cause warming over the Antarctic Peninsula (AP) and adjacent regions in West Antarctica and the Weddell Sea. In contrast, cooling occurs in East Antarctica, the eastern Ross Ice Shelf and parts of Marie Byrd Land. Most of the annual temperature signal stems from the months March-August. The spatial distribution of the precipitation response to changes in the AAO does not mirror temperature changes but is in first order determined by the direction of flow anomalies with respect to the Antarctic topography. When the vortex is strong (high AAO index), the western AP becomes wetter, while the Ross Ice Shelf, parts of West Antarctica and the Lambert Glacier basin, East Antarctica, become drier.
\end{abstract}

\section{INTRODUCTION}

Temperature trends in Antarctica have not been uniform in recent decades. A strong warming in the Antarctic Peninsula $\left(2.5^{\circ} \mathrm{C}\right.$ in the last 45 years) (Vaughan and others, 2001; King and others, 2003) has led to the rapid disintegration of the northern ice shelves (Vaughan and Doake, 1996), likely caused by increased meltwater ponding and associated iceshelf weakening (Scambos and others, 2000). On the other hand, a rapid cooling between 1986 and 2000 has been signalled in the Dry Valleys, Victoria Land, East Antarctica (Doran and others, 2002). This asymmetry in Antarctic temperature trends has been ascribed to Southern Hemisphere circulation variability. On month-to-month timescales, the dominant mode of variability of the Southern Hemisphere extratropical circulation is the Antarctic Oscillation (AAO) (Thompson and Wallace, 2000; Hall and Visbeck, 2002). The AAO represents the periodical strengthening and weakening of the circumpolar vortex, the belt of tropospheric westerlies surrounding the Antarctic continent. It is also named Southern Annular Mode because it has an approximate polar-symmetric shape. The AAO is a true standing mode, i.e. it does not resemble a propagating wave like the Antarctic Circumpolar Wave (White and Peterson, 1996); the latter explains a significant part of Antarctic climate variability on multi-annual time-scales (White, 2004).

Unfortunately, meteorological observations in Antarctica suffer from various problems: the station density is low and station locations are heavily biased towards the coast, where gradients in meteorological variables and topography are at their greatest and local influences potentially large. The Antarctic observational record is relatively short $(<50$ years)

*Present address: British Antarctic Survey, Natural Environment Research Council, Madingley Road, Cambridge CB3 OET, UK. and the large natural climate variability reduces the significance of trends. To structure the Antarctic climate record, it is clear that we must resort to modelling and remote-sensing techniques.

Many researchers have used US National Centers for Environmental Prediction/National Center for Atmospheric Research (NCEP/NCAR) re-analysis (1948-2002) (NRA) data to study Southern Hemisphere climate variability (Kalnay and others, 1996). Unfortunately, no pre-1968 Antarctic observations were used in the analysis, and before 1970 NRA suffers from unphysical mass loss at high southern latitudes (Hines and others, 2000). Comparison with radiosonde data shows that NRA data have limited accuracy in the Antarctic region (Marshall 2002a). Given the scarcity of observations before the satellite era, any future re-analysis of the climate of Antarctica before the early 1970s will also remain uncertain.

Recent studies used remotely sensed Antarctic temperatures to solve the problem of poor data coverage over the continent. Comiso (2000) compiled a dataset of Antarctic surface temperatures from satellite thermal infrared observations. These data were used by King and Comiso (2003) to study the spatial coherence of Antarctic Pensinsula (AP) warming and by Kwok and Comiso (2002) to analyze the response of Antarctic temperatures to the AAO and to the EI Niño-Southern Oscillation. Schneider and Steig (2002) used Antarctic ice-sheet microwave brightness temperatures to study Antarctic climate variability. Problems specific to remotely sensed temperature data are the temporal and spatial biases associated with cloud cover in the thermal infrared (Shuman and Comiso, 2002) and snowpack penetration and non-stationarity of the microwave emissivity for brightness temperatures.

In this paper, we use regression analysis on output of a regional atmospheric climate model (RACMO/ANT1; Van Lipzig, 1999) to investigate in more detail the influence of 


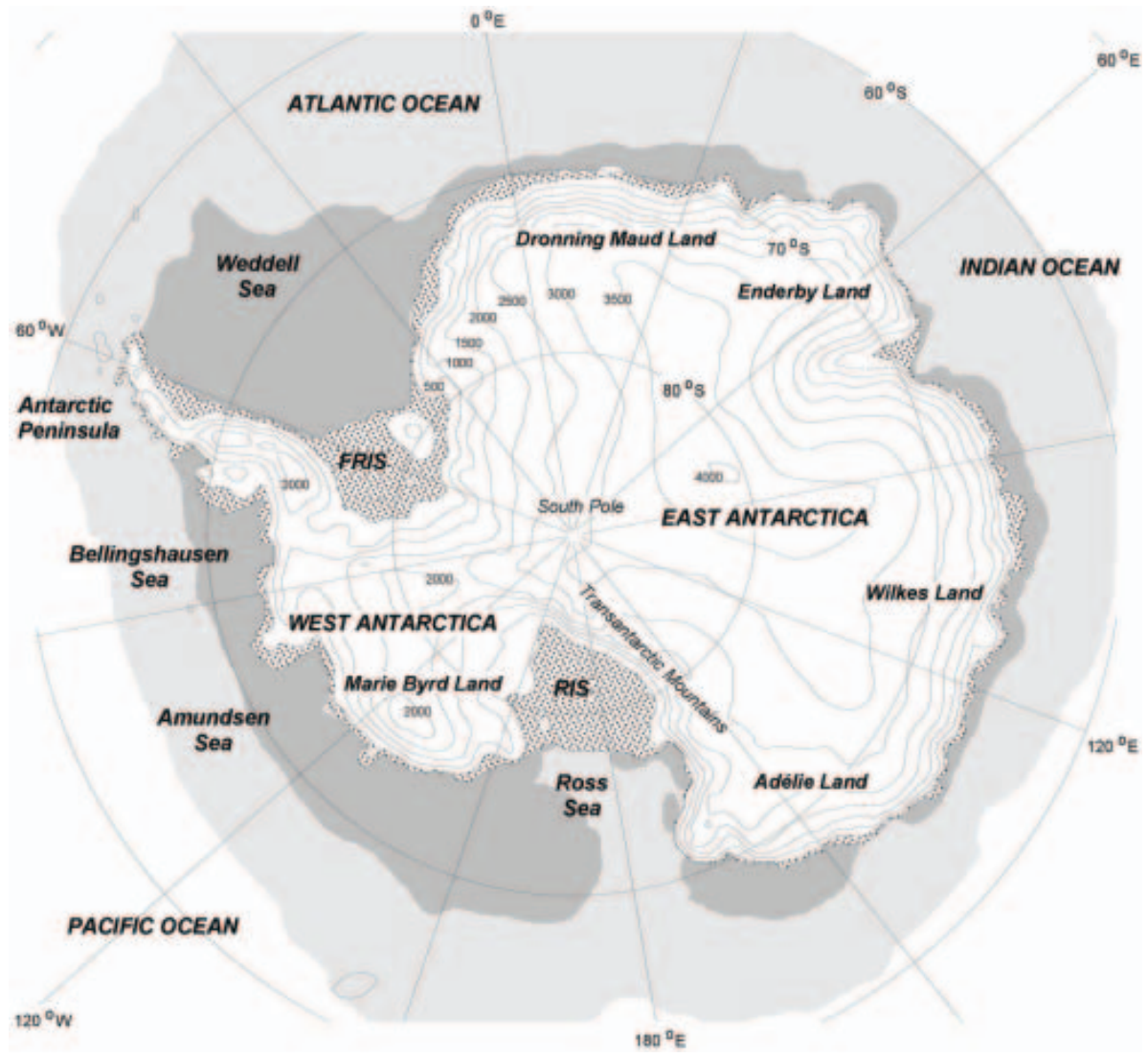

Fig. 1. Model domain and topography. Stippled areas: ice shelves; light shaded: average July sea-ice extent: dark shaded: average January sea-ice extent. Surface elevation (ma.s.I.) is contoured every 500 m. RIS, Ross Ice Shelf; FRIS, Filchner-Ronne Ice Shelf.

the AAO on the near-surface temperature, wind and precipitation in Antarctica.

\section{MODEL AND DATA}

RACMO/ANT1 is based on the ECHAM4 model of the Max Planck Institüt für Meteorologie. The RACMO/ANT1 domain of $122 \times 130$ gridpoints covers the Antarctic continent and part of the surrounding oceans (Fig. 1). The horizontal resolution of approximately $55 \mathrm{~km} \times 55 \mathrm{~km}$ enables a reasonably accurate representation of the coastal ice slopes and the ice shelves fringing the coast. In the vertical, 20 hybrid levels are used. An additional layer at 6-7 m above the surface was included to better capture the strong temperature and wind-speed gradients near the surface. At the lateral boundaries, RACMO/ANT1 is forced by European Centre for Medium-Range Weather Forecasts (ECMWF) reanalysis (1980-93, ERA 15). Daily variations in sea-ice cover and sea surface temperatures are prescribed from observations. The modelling technique is described in more detail in Van Lipzig and Van den Broeke (2002). The performance of RACMO/ANT1 is a great improvement on earlier models; for instance, the decoupling of the lowest atmospheric layer under conditions of strong stability that occurs in ERA 15 is absent in RACMO/ANT1, which uses a more sophisticated turbulence scheme. In a detailed comparison with station data, Van Lipzig (1999) and Van Lipzig and others (1999) showed that annual mean temperature, wind speed and directional constancy are simulated with root-mean-square errors of $1.5 \mathrm{~K}, 2 \mathrm{~m} \mathrm{~s}^{-1}$ and 0.12 .

Because the RACMO/ANT1 model domain is too small to calculate hemispheric circulation indices from, we use the
1980-93 monthly mean AAO index based on the first principal component of the NRA $850 \mathrm{hPa}$ extratropical height field $\left(20-90^{\circ} \mathrm{S}\right.$; Thompson and Wallace, 2000). Because this AAO index shows an upward trend that is associated with unphysical atmospheric mass loss at high southern latitudes (Hines and others, 2000), we use the detrended 1980-93 AAO time series (Fig. 2). As can be seen, the AAO is very variable on monthly time-scales and does not exhibit any coherent interannual behaviour. High values of the AAO index indicate a strong circumpolar vortex and low-amplitude Rossby waves in the polar front, while low values of the AAO index indicate a weak circumpolar vortex and high-amplitude Rossby waves.

\section{REPRESENTATION OF PRESENT-DAY CLIMATE}

Figure 3a-d show modelled annual mean (1980-93) surface pressure $p_{\mathrm{s}}$ (over the ocean only), $10 \mathrm{~m}$ wind speed and vector $V_{10 \mathrm{~m}}$, surface potential temperature $\theta_{\mathrm{s}}$ and total precipitation $P$. Here we present $\theta_{\mathrm{s}}$ instead of absolute temperature $T_{\mathrm{s}}$ because the latter is dominated by the elevation effect. However, all subsequent regressions are performed using $T_{\mathrm{s}}$ to avoid the pressure dependency of $\theta_{\mathrm{s}}$. To enable subsequent sections to be better understood, a brief discussion of the main climate features is given below.

The model faithfully reproduces the structure of the circumpolar trough (CPT) in surface pressure with its three climatological pressure minima (Fig. 3a). North of the CPT we find strong westerlies prevailing near the surface, while south of the CPT easterlies are found in the Antarctic coastal zone (Fig. 3b). Over the coastal ice sheet we see a welldeveloped katabatic wind system with annual mean $10 \mathrm{~m}$ 


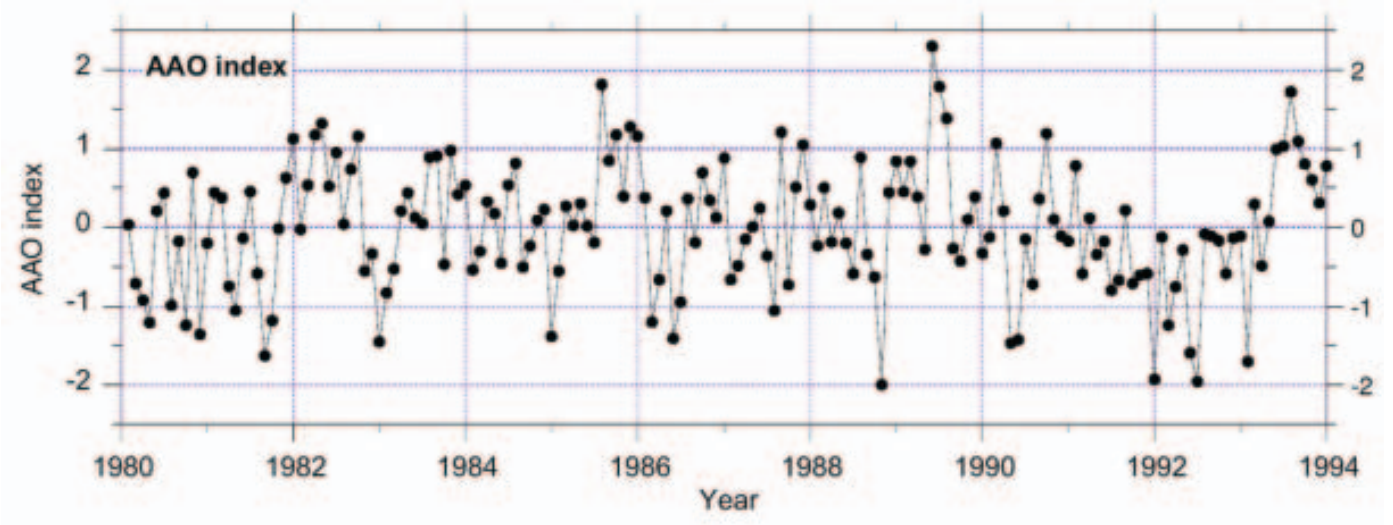

Fig. 2. Time series of detrended monthly mean AAO index, 1980-93.

wind speeds of 10-15 $\mathrm{m} \mathrm{s}^{-1}$. In the absence of a significant slope to force katabatic winds, the flat ice-sheet domes and ice shelves are characterized by relatively low wind speeds, typically $5 \mathrm{~m} \mathrm{~s}^{-1}$. Unrealistically low values of $10 \mathrm{~m}$ wind speed are modelled in regions where the model surface roughness for momentum has an important subgrid-topographical component (Transantarctic Mountains, parts of Dronning Maud Land and the AP). These values should not be compared to locally observed values.

High values of surface potential temperature $\theta_{\mathrm{s}}$ (Fig. 3c) are found over the coastal ice sheet; these are 'warm signatures' of katabatic winds that mix relatively warm air towards the surface (Bromwich, 1989; Van den Broeke and others, 1999). Low values of $\theta_{\mathrm{s}}$ are found over the flat icesheet interior, ice shelves and sea ice. These areas are characterized by a surface temperature inversion (Connolley, 1996). Note the close relation between the large-scale circulation, with these 'pools' of cold air, and northward sea-ice extent: the greatest northward extent of sea ice is found to the west of the climatological low-pressure areas, where northward advection of cold air is promoted. In the Ross and Weddell Seas these circulation systems are referred to as the Ross and Weddell gyres. The formation of Antarctic Bottom Water in these regions plays a major role in driving the global ocean circulation. Variations in the strength of these 'gyres' are important for the sensitivity of Antarctic temperature to changes in the large-scale circulation.

The largest annual precipitation amounts (Fig. 3d) in Antarctica are found in the western AP, coastal West Antarctica and coastal Wilkes Land (about 1000$1500 \mathrm{~mm}$ w.e.). These regions are characterized by strong interaction of the ice-sheet topography with the large-scale flow, resulting in forced convection. The interior of East Antarctica receives $<100 \mathrm{~mm}$ w.e. $\mathrm{a}^{-1}$ of precipitation. No maps of observed precipitation in Antarctica are available, but the modelled precipitation minus sublimation $(P-E$; not shown) is in qualitative agreement with recent compilations of Antarctic mass balance (Vaughan and others, 1999). All precipitation in Antarctica falls as snow, except for occasional rainfall events reported in the northernmost AP.

\section{AAO REGRESSION RESULTS}

We regressed monthly mean anomalies of surface pressure $p_{\mathrm{s}}$, surface temperature $T_{\mathrm{s}}$, precipitation $P$ and $10 \mathrm{~m}$ wind speed and wind vector components $\left(U_{10 \mathrm{~m}}, V_{10 \mathrm{~m}}\right)$ onto the monthly mean detrended AAO index, 1980-93 $(N=168)$. The fields presented in this section are thus representative of a strengthening of the circumpolar vortex (from low to high AAO index). The slopes of the linear regressions were multiplied by the standard deviation of the AAO index (0.81) to obtain anomaly fields that have units of the dependent variable and are related to 1 standard deviation of the AAO index (Fig. 4a-d). Dashed contours delineate areas where correlation confidence reaches $99 \%$. The time series of AAO index in Figure 2 do not display significant autocorrelation, so no correction was applied for this.

\section{Surface pressure and $10 \mathrm{~m}$ wind}

The surface pressure anomaly pattern (Fig. 4a) shows strongly negative values over continental Antarctica and positive values at lower latitudes, a common feature of the AAO. Except for a small band around zero change, the $99 \%$ confidence level is reached everywhere and is not shown. In spite of the 'annular' character of the AAO, the pattern in Figure $4 \mathrm{a}$ is far from zonally symmetric, because of the climatological low-pressure centres around Antarctica (Fig. 3a). In Figure 4a, a pronounced surface pressure decrease is found in the Amundsen Sea, which coincides with the 'pole of variability' in the Southern Hemisphere and is associated with a changed location of the AmundsenBellingshausen Sea low (Connolley, 1997). A weaker local minimum is found over Wilkes Land, East Antarctica. The maximum gradient in the surface pressure anomaly field occurs just north of the Antarctic coastline and represents an increase of the surface geostrophic zonal wind of about $2 \mathrm{~m} \mathrm{~s}^{-1}$. At $500 \mathrm{hPa}$, zonal winds have increased by about twice this amount (not shown), indicative of an enhanced horizontal meridional temperature gradient under conditions of positive AAO polarity.

Figure $4 \mathrm{~b}$ presents $10 \mathrm{~m}$ wind anomalies, expressed as a vector composed of the anomalies in the individual horizontal components. Background colours indicate changes in absolute wind speed. Following the annular character of surface pressure anomalies (Fig. 4a), a $1 \mathrm{~m} \mathrm{~s}^{-1}$ increase of the westerlies north of Antarctica is found, i.e. about half of the change in the surface geostrophic wind speed. Some important deviations from zonal symmetry occur over the continent: flow anomalies are directed towards West Antarctica where they cross the West Antarctic ice divide and descend towards the Ross Ice 

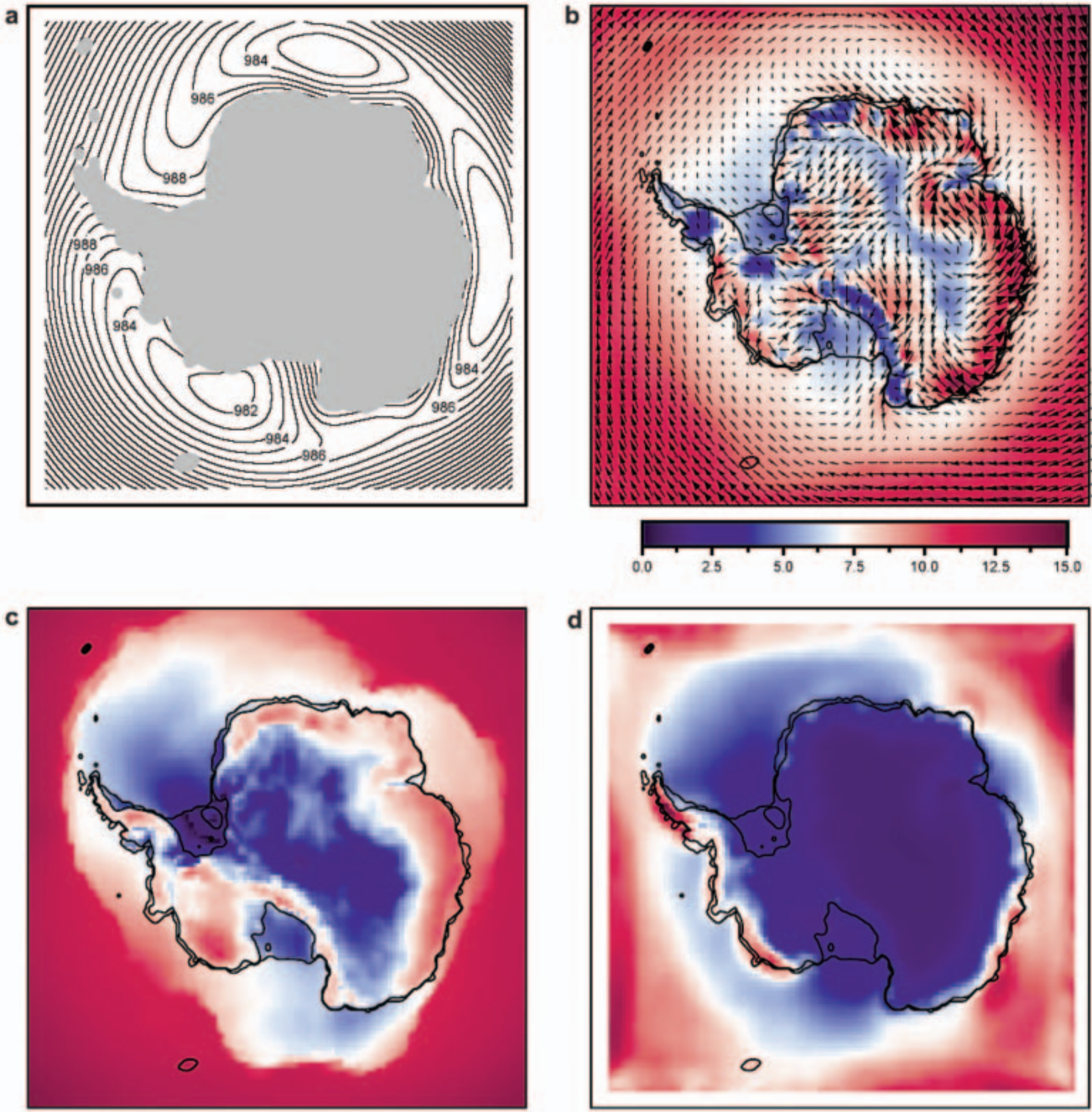

d

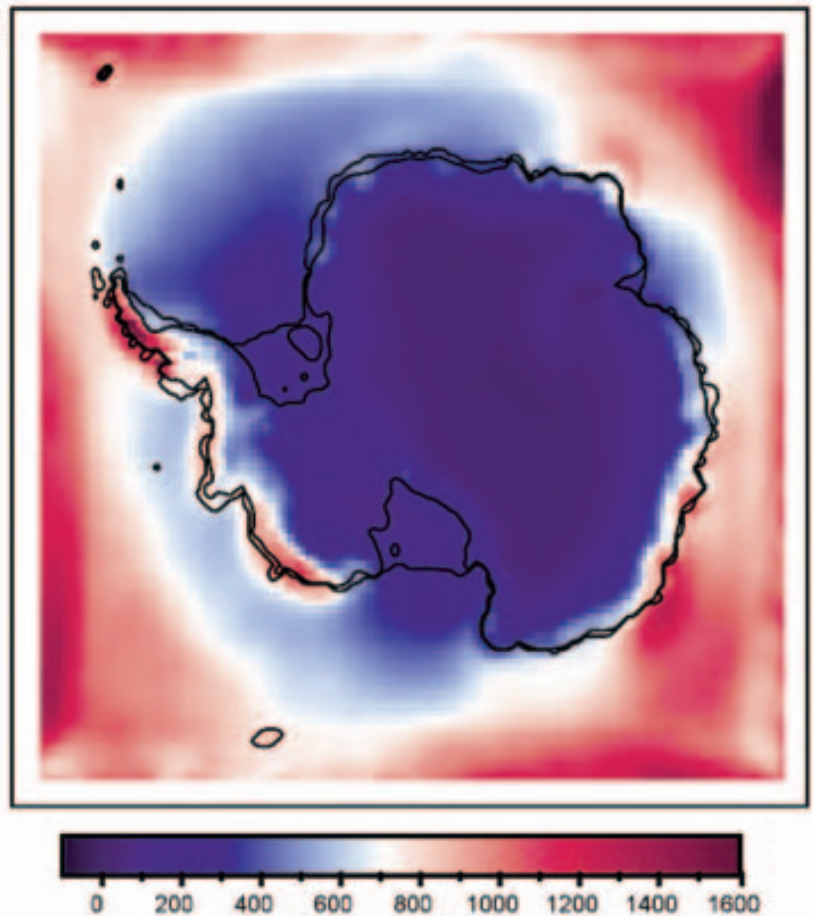

Fig. 3. (a) 1980-93 modelled annual mean sea-level pressure in $\mathrm{hPa}$; (b) $10 \mathrm{~m}$ vector wind and wind speed (background colour) in $\mathrm{m} \mathrm{s}^{-1}$; (c) surface potential temperature in $\mathrm{K}$; and (d) annual precipitation in $\mathrm{mm}$.

Shelf. In the Weddell Sea, northerly flow anomalies follow the east coast of the AP, continuing over the Filchner-Ronne Ice Shelf and on to the East Antarctic plateau. This represents a weakening of the persistent southerly flow along the eastern border of the AP, which Schwerdtfeger (1975) identified as barrier winds. Anomalous southerly geostrophic flow occurs over the Ross Ice Shelf and in western Dronning Maud Land.

The sign of the wind-speed anomaly (background colours in Fig. 4b) depends on whether the vector wind anomaly has a component in the direction of the local climatological wind direction or opposed to it (cf. vectors in Figs $2 \mathrm{~b}$ and $4 \mathrm{~b}$ ). For example, over the ocean and sea ice, the pressure anomaly field enhances the westerlies north of the CPT by up to $1 \mathrm{~m} \mathrm{~s}^{-1}$ but weakens the coastal easterlies along the East Antarctic coast by a similar amount. Over the ice sheet, the climatological wind direction is determined mainly by the katabatic component which acts in the downslope direction. This generates cross-slope winds with a downslope component near the surface due to friction (Fig. 2b) (Van den Broeke and others, 2002).

The dependency of the near-surface katabatic wind field 

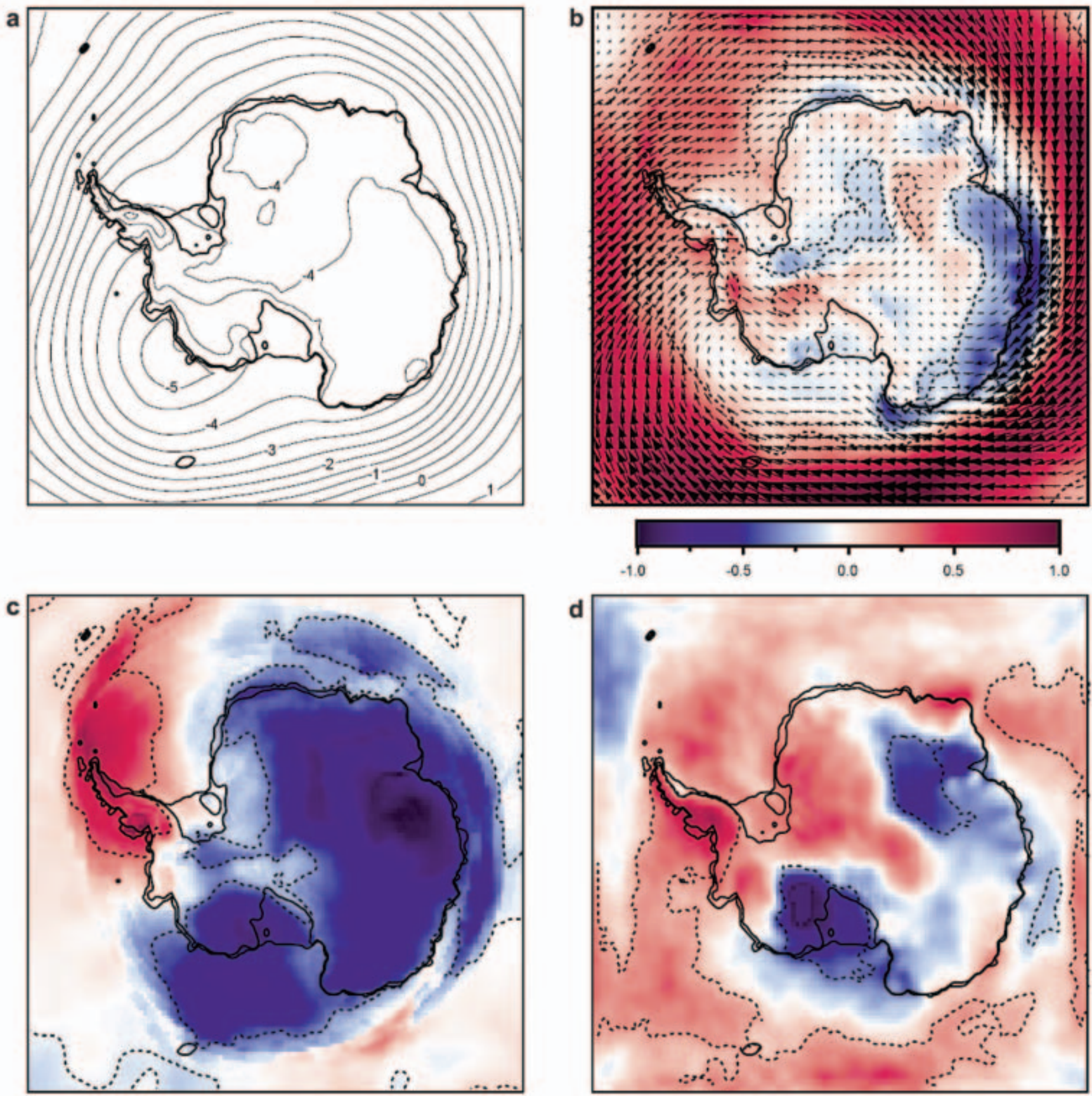

d
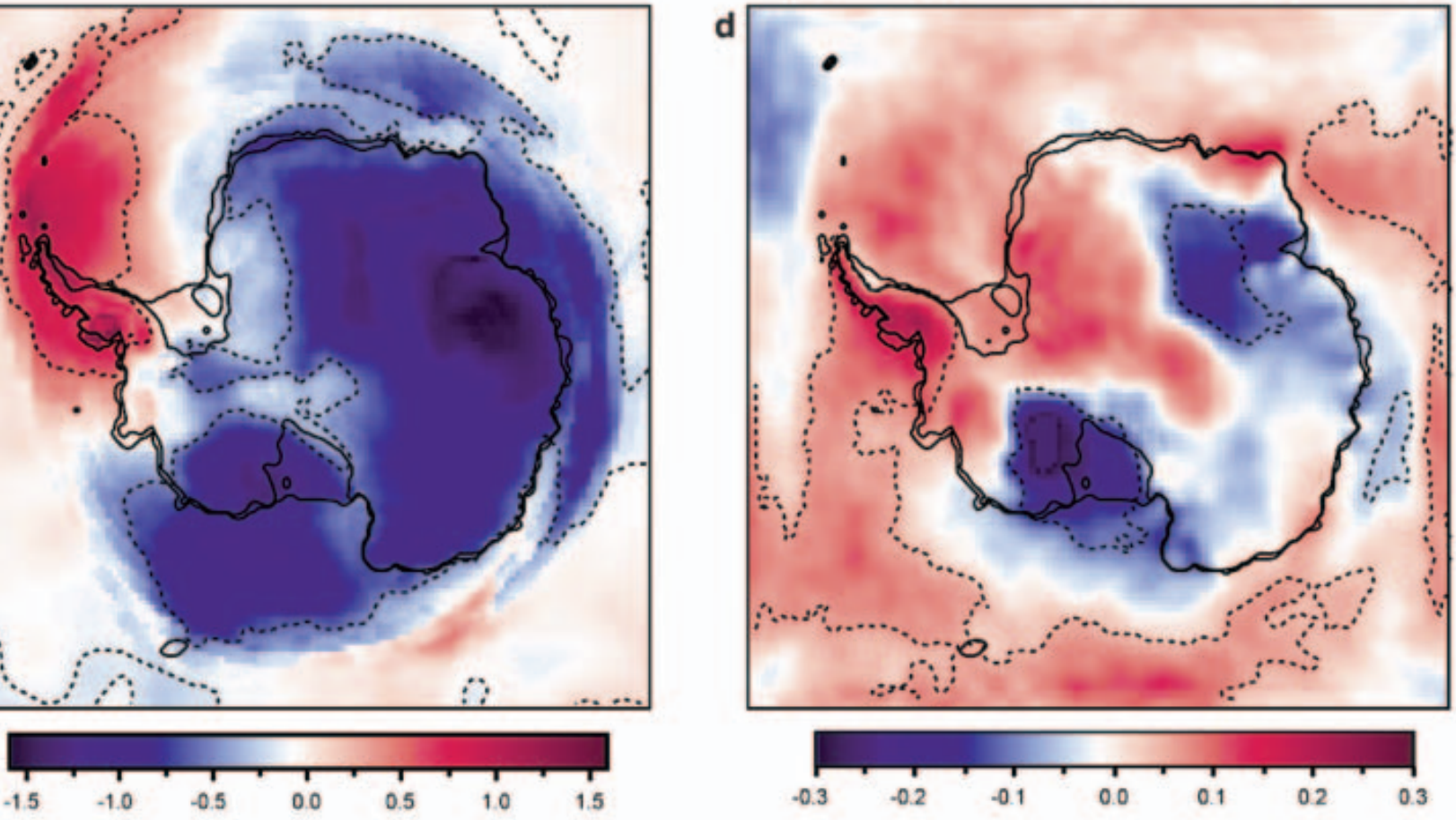

Fig. 4. (a) AAO regression slope of surface pressure in hPa; (b) $10 \mathrm{~m}$ vector wind and wind speed (background colour) in $\mathrm{m} \mathrm{s}^{-1}$; (c) surface potential temperature in $\mathrm{K}$; and (d) annual precipitation in \%. Values correspond to a 1 standard deviation anomaly in the AAO. Dashed contours enclose areas where the $99 \%$ confidence level is reached.

on slope direction explains the dipole patterns of $10 \mathrm{~m}$ windspeed change that are seen in interior Dronning Maud Land and in West Antarctica in Figure 4b. In Wilkes Land, the large-scale pressure-gradient force (PGF) and the katabatic PGF generally act in the same direction, i.e. downslope. In this region, both PGFs become equally important in the near-surface momentum budget (Parish and Cassano, 2001; Van den Broeke and Van Lipzig, 2003). Because the perturbation large-scale PGF is directed opposite to the average large-scale PGF, a marked decrease in near-surface wind speed is found in this area (Fig. 4b).

\section{Surface temperature}

A stronger circumpolar vortex (high AAO index) induces significant cooling over most of East Antarctica, and significant warming over the entire AP (Fig. 4c). This pattern is very similar to that presented by Kwok and Comiso (2002) who used surface temperatures derived from thermal infrared imagery (1982-99). For wintertime conditions, Van den Broeke and Van Lipzig (2002) showed that East Antarctic cooling during strong vortex conditions has two components: a general tropospheric cooling of about $2 \mathrm{~K}$ over 

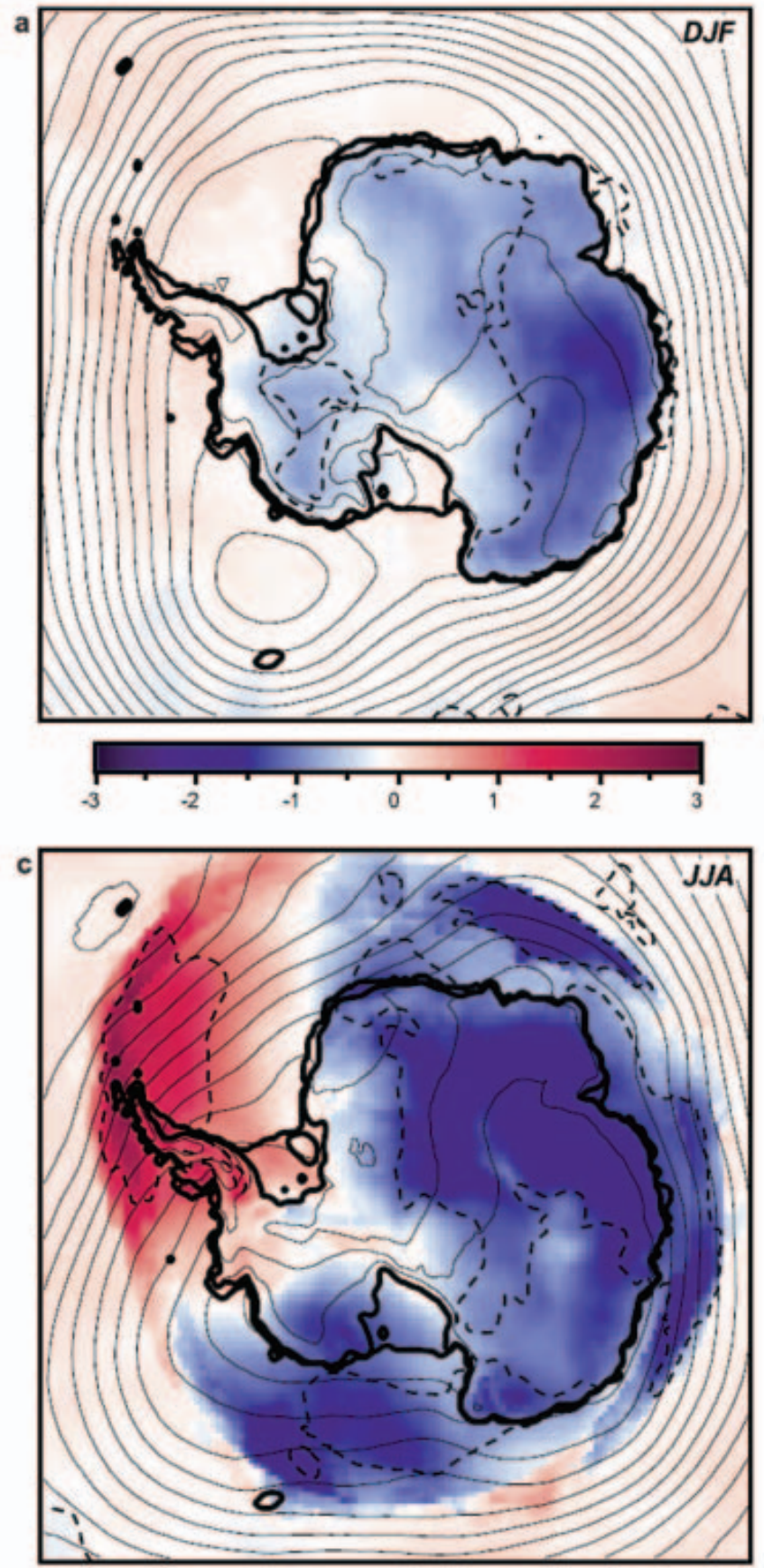
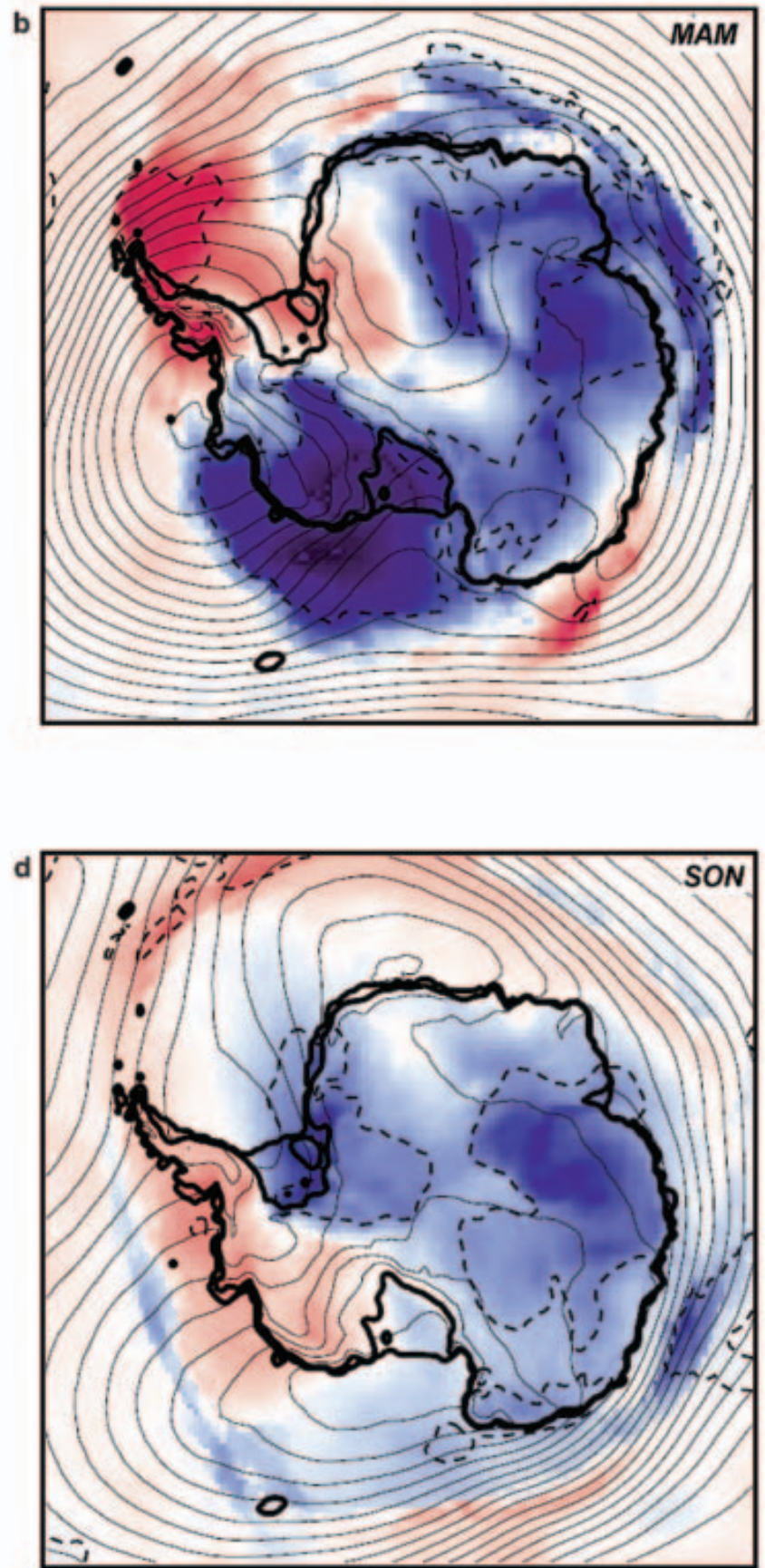

Fig. 5. Seasonal subsets of AAO regression slope of surface pressure in $\mathrm{hPa}$ (solid contours) and surface temperature in $\mathrm{K}$ (colours) for DJF (a), MAM (b), JJA (c) and SON (d). Values correspond to a 1 standard deviation anomaly in the AAO. Dashed contours enclose areas where the $99 \%$ confidence level is reached.

the whole of East Antarctica, probably caused by suppressed meridional air exchange, and additional cooling near the surface in areas where a weakening of near-surface winds has intensified the surface temperature inversion.

From Figure 4c it appears that areas with a surface temperature inversion (roughly coinciding with low potential temperatures in Fig. 2c) are prone to potentially stronger surface warming when the circumpolar vortex is strong (high $\mathrm{AAO}$ index) through destruction of the temperature inversion. An example is the AP ice shelves, where warming is larger than in the immediate surroundings. This process may be dominated by changes in horizontal heat advection in regions where flow anomalies are directed perpendicular to large horizontal temperature gradients such as are found near the continental margin and the sea-ice edge. For instance, the strong warming over the western AP and the Weddell Sea is likely to be at least partly caused by a greater northerly wind component in combination with decreased sea-ice cover in the Bellingshausen Sea (Marshall and King, 1998; Marshall, 2002b). A more quantitative assessment of the contributions of various processes to regional temperature change, based on calculation of the individual terms in the heat budget, is a topic of future study.

\section{Precipitation}

When the circumpolar vortex is strong (high AAO index), three areas over the continent show changes in precipitation that reach the $99 \%$ confidence level (Fig. 4d). An increase of 
up to $30 \%$ is found over the western AP, while western Marie Byrd Land and the adjacent Ross Ice Shelf show decreases of a similar magnitude. Interestingly, in the precipitation shadow at the eastern side of the AP, zero precipitation change is found over the northerly ice shelves; an increase in their mass balance may have slowed down their disintegration. A relative decrease of about $15 \%$ is found over the Lambert Glacier basin. These patterns clearly reflect the interaction between circulation anomalies (Fig. 4a and b) and Antarctic topography. Of interest to ice-core researchers is that western Dronning Maud Land experiences a precipitation increase of up to $10 \%$ (mostly reaching the 90-95\% confidence level) and at the same time significant cooling (Fig. 4c). Elsewhere in Antarctica, increases in precipitation are in general associated with warming.

\section{Regression on seasonal subsets}

It is well known that the Antarctic temperature inversion is strongest in winter and greatly reduced in summer. Other important factors determining Antarctic surface temperature, such as sea-ice extent and strength of the katabatic winds, also show a pronounced annual cycle. From this we would expect a seasonal dependence of the temperature response to the AAO. To investigate this, we regressed seasonal subsets of 3 months (DJF, MAM, JJA and SON) on the AAO index. Figure 5 shows the combined results for surface temperature (colours, dashed contours where 99\% confidence is reached) and surface pressure (solid contours). In spite of the reduced number of points used in the regression, all seasons show extensive areas with significant surface cooling over East Antarctica in response to a stronger circumpolar vortex (high AAO index). For instance, in Wilkes Land just east of the Lambert Glacier basin, cooling is significant in all four seasons. Warming in the AP is most pronounced in autumn and winter, when the circulation anomalies have their greatest northerly component, so that most of the annual temperature signal in Figure 4c derives from the months March-August (Fig. 5b and c). This is in agreement with observations (Marshall, 2002a).

\section{Impact of wind and temperature changes on the surface sensible heat flux}

To investigate what causes the surface cooling in East Antarctica under conditions of strong circumpolar vortex (high AAO index), we selected from Figure 4c the location in Wilkes Land where the correlation between the AAO index and temperature attains a minimum. For this location, Figure 6 shows the correlation between the AAO index and anomalies in the surface turbulent flux of sensible heat (SHF). SHF is an important component of the wintertime Antarctic surface energy balance, and provides the surface with heat that it loses through net emission of longwave radiation. Because turbulence and hence the SHF in the stably stratified wintertime Antarctic atmosphere is generated mainly by wind shear, a decrease in $10 \mathrm{~m}$ wind leads to a decrease in SHF and hence a lower surface temperature. This link of the AAO with East Antarctic surface temperatures through the katabatic wind field and the sensible heat flux is clearly apparent from Figure 6.

\section{SUMMARY AND FUTURE WORK}

We used output of a 14 year integration with a high-resolution regional atmospheric climate model (RACMO/ANT1)

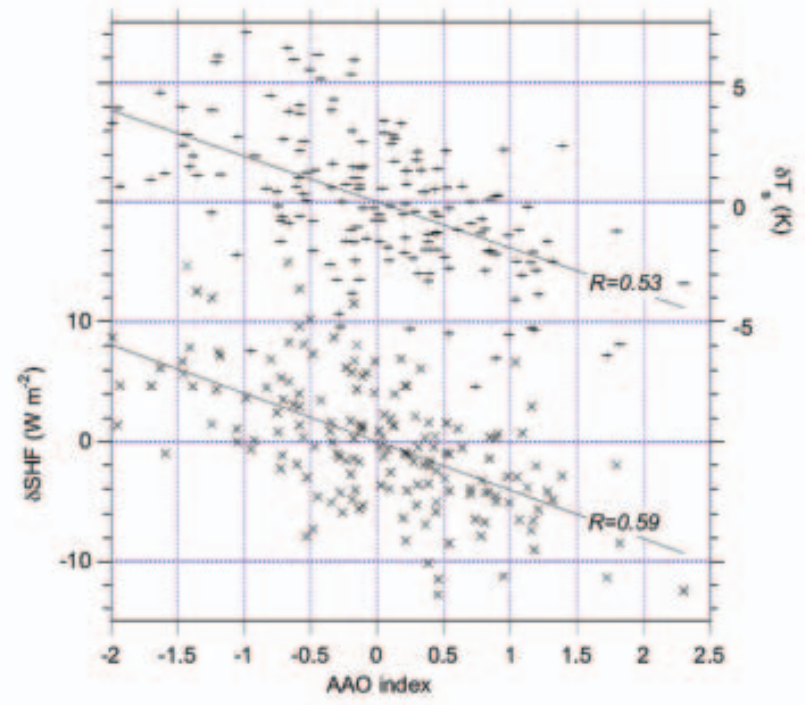

Fig. 6. Correlation of monthly-mean AAO index (1980-93) with anomalies of surface temperature and turbulent flux of sensible heat for a centre of action in Wilkes Land (see white cross in Fig. 4c).

to study the response of the (near-) surface Antarctic climate to the AAO, which is a measure of the strength of the circumpolar vortex or westerlies. In spite of the relatively short period, significant AAO-related anomalies were found in surface pressure, $10 \mathrm{~m}$ wind, surface temperature and precipitation. When the vortex is strong (high AAO index), surface pressure changes show an asymmetric pattern, with the largest pressure falls in coastal Marie Byrd Land. This causes northerly flow anomalies and significant warming over the AP and adjacent regions in West Antarctica and the Weddell Sea. In response to decreased meridional air exchange and weaker near-surface winds, significant cooling occurs throughout East Antarctica. The strongest signals are found in Wilkes Land, but strong cooling is also found over the Ross Ice Shelf and the adjacent part of West Antarctica. Repeating the regression on subsets of 3 months reveals that most of the annual temperature signal derives from the months March-August. Precipitation anomalies reflect the interaction of circulation anomalies and topography and do not generally mirror temperature changes. Significant wet anomalies are found on the western AP, and dry anomalies occur over the Ross Ice Shelf, the adjacent West Antarctic ice sheet and in the Lambert Glacier basin, East Antarctica.

The regional modelling approach has proved very useful for clarifying physical processes underlying climate change in Antarctica. To improve statistical significance in studies of this kind, a 45 year run with a regional atmospheric climate model (forced by ERA40) is ongoing.

\section{REFERENCES}

Bromwich, D.H. 1989. Satellite analyses of Antarctic katabatic wind behavior. Bull. Am. Meteorol. Soc., 70(7), 738-749.

Comiso, J.C. 2000. Variability and trends in Antarctic surface temperatures from in situ and satellite infrared measurements. J. Climate, 13(10), 1674-1696.

Connolley, W. M. 1996. The Antarctic temperature inversion. Int. J. Climatol., 16(12), 1333-1342. 
Connolley, W. M. 1997. Variability in annual mean circulation in southern high latitudes. Climate Dyn., 13(10), 745-756.

Doran, P. T. and 12 others. 2002. Antarctic climate cooling and terrestrial ecosystem response. Nature, 415(6871), 517-520.

Hall, A. and M. Visbeck. 2002. Synchronous variability in the Southern Hemisphere atmosphere, sea ice and ocean resulting from the annular mode. J. Climate, 15(2), 3043-3057.

Hines, K. M., D. H. Bromwich and G.J. Marshall. 2000. Artificial surface pressure trends in the NCEP-NCAR reanalysis over the Southern Ocean and Antarctica. J. Climate, 13(22), 3940-3952.

Kalnay, E. and 21 others. 1996. The NCEP/NCAR 40 year reanalysis project. Bull. Am. Meteorol. Soc., 77(3), 437-471.

King, J.C. and J.C. Comiso. 2003. The spatial coherence of interannual temperature variations in the Antarctic Peninsula. Geophys. Res. Lett., 30(2), 1040. (10.1029/2002GL015580.)

King, J.C., J. Turner, G.J. Marshall, W. M. Connolley and T. A. Lachlan-Cope. 2003. Antarctic Peninsula climate variability and its causes as revealed by analysis of instrumental records. In Domack, E.W., A. Burnett, A. Leventer, P. Conley, M. Kirby and R. Bindschadler, eds. Antarctic Peninsula climate variability: a historical and paleoenvironmental perspective. Washington, DC, American Geophysical Union, 17-30. (Antarctic Research Series 79.)

Kwok, R. and J. C. Comiso. 2002. Spatial patterns of variability in Antarctic surface temperature: connections to the Southern Hemisphere annual mode and the Southern Oscillation. Geophys. Res. Lett., 29(14). (10.1029/2002GL015415.)

Marshall, G. J. 2002a. Analysis of recent circulation and thermal advection change in the northern Antarctic Peninsula. Int. J. Climatol., 22(12), 1557-1567.

Marshall, G. J. 2002b. Trends in Antarctic geopotential height and temperature: a comparison between NCEP-NCAR and radiosonde data. J. Climate, 15(6), 659-674.

Marshall, G.J. and J. C. King. 1998. Southern Hemisphere circulation anomalies associated with extreme Antarctic Peninsula winter temperatures. Geophys. Res. Lett., 25(13), 2437-2440.

Parish, T.R. and J.J. Cassano. 2001. Forcing of the wintertime Antarctic boundary layer winds from the NCEP-NCAR global reanalysis. J. Appl. Meteorol., 40(4), 810-821.

Scambos, T. A., C. Hulbe, M. Fahnestock and J. Bohlander. 2000. The link between climate warming and break-up of ice shelves in the Antarctic Peninsula. J. Glaciol., 46(154), 516-530.

Schneider, D.P. and E.J. Steig. 2002. Spatial and temporal variability of Antarctic ice sheet microwave brightness temperatures. Geophys. Res. Lett., 29(20), 1964. (10.1029/ 2002GL015490.)

Schwerdtfeger, W. 1975. The effect of the Antarctic Peninsula on the temperature regime of the Weddell Sea. Mon. Weather Rev., 103(1), 45-51.
Shuman, C.A. and J.C. Comiso. 2002. In situ and satellite surface temperature records in Antarctica. Ann. Glaciol., 34, 113-120.

Thompson, D. W. J. and S. Solomon. 2002. Interpretation of recent Southern Hemisphere climate change. Science, 296(5569), 895-899.

Thompson, D. W. J. and J. M. Wallace. 2000. Annular modes in the extratropical circulation. Part I: Month-to-month variability. J. Climate, 13(5), 1000-1016.

Van den Broeke, M.R. and N. P.M. van Lipzig. 2002. Impact of vortex variability on the wintertime low-level climate of East Antarctica: results of a regional climate model. Tellus, 54A(5), 485-496.

Van den Broeke, M.R. and N.P.M. van Lipzig. 2003. Factors controlling the near surface wind field in Antarctica. Mon. Weather Rev., 131(4), 733-743.

Van den Broeke, M. R. and 6 others. 1999. Climate variables along a traverse line in Dronning Maud Land, East Antarctica. J. Glaciol., 45(150), 295-302.

Van den Broeke, M. R., N. P. M. van Lipzig and E. van Meijgaard. 2002. Momentum budget of the East-Antarctic atmospheric boundary layer: results of a regional climate model. J. Atmos. Sci., 59(21), 3117-3129.

Van Lipzig, N.P.M. 1999. The surface mass balance of the Antarctic ice sheet: a study with a regional atmospheric model. (Ph.D. thesis, Utrecht University.)

Van Lipzig, N. P. M. and M. R. van den Broeke. 2002. A model study on the relation between atmospheric boundary-layer dynamics and poleward atmospheric moisture transport in Antarctica. Tellus, 54A(5), 497-511.

Van Lipzig, N.P.M., E. van Meijgaard and J. Oerlemans. 1999. Evaluation of a regional atmospheric model using measurements of surface heat exchange processes from a site in Antarctica. Mon. Weather Rev., 127(9), 1994-2001.

Vaughan, D. G. and C.S.M. Doake. 1996. Recent atmospheric warming and retreat of ice shelves on the Antarctic Peninsula. Nature, 379(6563), 328-331.

Vaughan, D.G., J.L. Bamber, M. B. Giovinetto, J. Russell and A. P. R. Cooper. 1999. Reassessment of net surface mass balance in Antarctica. J. Climate, 12(4), 933-946.

Vaughan, D. G., G.J. Marshall, W. M. Connolley, J.C. King and R. Mulvaney. 2001. Climate change: devil is in the detail. Science, 293(5536), 1777-1779.

White, W. B. 2004. Comments on 'Synchronous variability in the Southern Hemisphere atmosphere, sea ice and ocean resulting from the annular mode'. J. Climate, 17(11), 2249-2254.

White, W. B. and R. G. Peterson. 1996. An Antarctic circumpolar wave in surface pressure, wind, temperature and sea-ice extent. Nature, 380(6576), 699-702. 